\title{
DESEMPENHO, CARACTERÍSTICAS DA CARCAÇA E DA CARNE DE NOVILHOS PRECOCES TERMINADOS EM CONFINAMENTO ALIMENTADOS COM SORO DE LEITE
}

\author{
WEBER, André ${ }^{1}$ \\ ARBOITTE, Miguelangelo Ziegler ${ }^{2}$ \\ MARTINS, Carlos Eduardo Nogueira ${ }^{3}$ \\ KAZAMA, Ricardo ${ }^{4}$
}

\begin{abstract}
RESUMO: Objetivou-se avaliar o desempenho produtivo e características qualitativas da carcaça e da carne de bovinos de corte confinados. Foram utilizados 24 novilhos, de raças taurinas e suas cruzas, com peso corporal inicial de 319,3 $\pm 11,4 \mathrm{~kg}$ e idade de 11 meses, distribuídos em delineamento experimental inteiramente casualizado, sendo 2 dietas e 3 repetições, em um período experimental de 124 dias. As dietas (Tratamentos) consistiram em uma dieta controle e uma dieta contendo soro de leite. As dietas apresentaram relação volumoso: concentrado de 40:60, contendo $13 \%$ de Proteína Bruta e $68 \%$ de Nutrientes Digestíveis Totais, compostas por silagem de milho e concentrado. Na dieta soro, foram incluídos $14,78 \%$ da MS da dieta de soro de leite. Os resultados apresentaram semelhanças ( $p>0,05)$ no ganho de peso médio diário $(1,42 \mathrm{~kg} / \mathrm{dia})$, pesos de abate $(497 \pm 19,94$ e $504 \pm 21,36 \mathrm{~kg})$, peso das carcaças quente $(279,15 \pm 12,54$ e $287,77 \pm 13,16 \mathrm{~kg})$, rendimento de carcaça quente $(56,02 \pm 0,50$ e $56,89 \pm 0,50 \%)$, espessura de gordura subcutânea $(5,25 \pm 0,92$ e $6,50 \pm 1,35 \mathrm{~mm})$, temperatura das carcaças $(7,17 \pm 0,27$ e

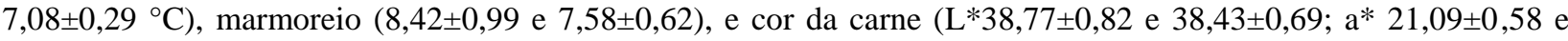
$20,02 \pm 0,58 ; b^{*} 12,44 \pm 0,35$ e $\left.11,45 \pm 0,44\right)$. Diferenças foram verificadas no consumo de MS, com valores de $9,39 \pm 0,15$ e $8,40 \pm 0,14 \mathrm{~kg} / \mathrm{animal} / \mathrm{dia}$ e nos valores do $\mathrm{pH} 6,02 \pm 0,09$ e $6,35 \pm 0,10$, respectivamente $(\mathrm{p}<0,05)$. O soro de leite inserido na dieta dos animais ao nível de inclusão de $14,79 \%$, não afetou o desempenho produtivo e a qualidade da carne.
\end{abstract}

Palavras-chave: Consumo. Ganho de peso. Qualidade da carne. Rendimento de carcaça.

\section{PERFORMANCE, CARCASS AND MEAT CHARACTERISTICS OF PRECOCIOUS STEERS FINISHED IN FEEDLOT FED MILK WHEY}

SUMMARY: The objective of this study was to evaluate the productive performance and qualitative characteristics of the carcass and meat of confined beef cattle. Twenty-four crossbred steers with initial body weight of $319.3 \pm 11.4$ $\mathrm{kg}$ and age of 11 months were used, distributed in a completely randomized experimental design, with 2 diets and 3 repetitions, in an experimental period 124 days. The diets (Treatments) consisted of a control diet and a diet containing whey. The diets showed a 40:60 roughage: concentrate ratio, containing 13\% crude protein and $68 \%$ total digestible nutrients, composed of corn silage and concentrate. In the whey diet, $14.78 \%$ of the whey diet DM were included. The results showed similarities ( $\mathrm{p}>0.05)$ in the average daily weight gain $(1.42 \mathrm{~kg} / \mathrm{day})$, slaughter weights $(497 \pm 19.94$ and $504 \pm 21.36 \mathrm{~kg}$ ), warm carcass weight $(279,15 \pm 12.54$ and $287.77 \pm 13.16 \mathrm{~kg}$ ), hot carcass yield $(56.02 \pm 0.50$ and $56.89 \pm 0.50 \%)$, subcutaneous fat thickness $(5.25 \pm 0,92$ and $6.50 \pm 1.35 \mathrm{~mm})$, carcass temperature (7.17 \pm 0.27 and $7.08 \pm 0.29^{\circ} \mathrm{C}$ ), marbling $(8.42 \pm 0.99$ and $7.58 \pm 0.62)$, and flesh color $\left(\mathrm{L}^{*} 38.77 \pm 0.82\right.$ and $38.43 \pm 0.69 ; a^{*} 21.09 \pm 0.58$ and $20.02 \pm 0.58 ; b^{*} 12,44 \pm 0.35$ and $\left.11.45 \pm 0.44\right)$. Differences were found in DM intake, with values of $9.39 \pm 0.15$ and $8.40 \pm 0.14 \mathrm{~kg} / \mathrm{animal} / \mathrm{day}$ and $\mathrm{pH} 6.02 \pm 0.09$ and $6.35 \pm 0,10$, respectively $(\mathrm{p}<0.05$ ). Whey inserted in the animals' diet at the inclusion level of $14.79 \%$ did not affect the productive performance and meat quality.

Keywords: Intake. Carcass yield. Meat quality. Weight gain.

\footnotetext{
${ }^{1}$ Pós graduando - Programa de Pós Graduação em Produção e Sanidade Animal do Instituto Federal Catarinense

${ }^{2}$ Instituto Federal Catarinense Campus Santa Rosa do Sul - Doutor, Professor Zootecnia - Rua das Rosas, s/n Bairro Vila Nova - Caixa postal 04 - CEP 88965-000 - Santa Rosa do Sul (SC), Brasil

${ }^{3}$ Instituto Federal Catarinense - Campus Araquarí - Doutor, professor Zootecnia - Rodovia BR 280 - km 27 - caixa postal 21 - CEP 89245-000 - Araquarí (SC), Brasil.

${ }^{4}$ Universidade Federal de Santa Catarina - Doutor, Departamento de Zootecnia e Desenvolvimento Rural - Rodovia Admar Gonzaga, 1346, Bairro Itacorubi - CEP 88034-000 - Florianópolis (SC), Brasil
} 


\section{INTRODUÇÃO}

O número de bovinos confinados no Brasil no ano de 2018 chegou a 5,58 milhões de cabeças, representando $12,6 \%$ do rebanho abatido no mesmo ano, que totalizou 44,23 milhões de cabeças (ABIEC, 2018), ficando sob a responsabilidade do Serviço de Inspeção de Produtos de Origem Animal (SIPAs/DFAs) 24.456.757 bovinos abatidos (BRASIL, 2018).

No sistema produtivo da pecuária de corte, o confinamento é uma atividade comumente exercida por vários pecuaristas. Entretanto, sua prática requer planejamento para que possa proporcionar lucratividade, principalmente devido aos elevados custos dos ingredientes que constituem a dieta dos animais. O sucesso da atividade está vinculado a vários fatores, mas merecem destaque e atenção especial o potencial para ganho de peso dos animais destinados ao confinamento e o custo da alimentação (LOPES; MAGALHÃES, 2005).

O preço dos grãos de cereais empregados na alimentação animal acaba impulsionando o uso de subprodutos da agroindústria na alimentação de ruminantes, que devido à presença da microbiota existentes no rúmen, transformam subprodutos ofertados nas dietas, em produtos de origem animal (carne e leite), desde que supram as exigências nutricionais das espécies e da categoria animal em produção (PASCHOALOTO, 2016; MORELLI et al, 2017).

A necessidade de conciliar produtividade, lucratividade e sustentabilidade na prática de atividades relacionadas à agropecuária, vem de encontro com a utilização de subprodutos da agroindústria para diminuir custos e o aumento da produção e da lucratividade, sem desprezar os aspectos ambientais (MELO et al., 2016; SILVA et al., 2019). Sob esse enfoque o sistema produtivo da pecuária de corte requer constantemente a produção eficiente, economicamente viável e capaz de fornecer produtos de alta qualidade, satisfazendo as exigências dos consumidores (BONILHA et al., 2007; MELO et al., 2016).

Um subproduto que tem sido disponibilizado pela agroindústria de laticínios para a alimentação animal é o soro de leite bovino, gerado durante o processo da fabricação de queijos, que em regiões onde existem indústrias transformadoras de leite em outros produtos é disponibilizado, sendo alternativa para a terminação de bovinos.

O objetivo do trabalho foi avaliar o desempenho produtivo, as características qualitativas da carne de bovinos de corte terminados em confinamento alimentados com soro de leite.

\section{MATERIAL E MÉTODO}


O estudo foi autorizado pelo Comitê de Ética no Uso de Animais do Instituto Federal Catarinense Campus Araquari (CEUA-IFC), sob número do protocolo do processo: 231/2017.

O experimento foi conduzido entre os meses de julho e novembro de 2018 em uma propriedade que realiza a atividade de confinamento de bovinos de corte, situada no município de São Bonifácio em Santa Catarina, com coordenadas $27^{\circ} 51^{\prime}$ latitude Sul e $48^{\circ} 57^{\prime}$ longitude Oeste, e a 473 metros de altitude. Apresentando temperaturas máxima e mínima de $25^{\circ} \mathrm{C}$ e $12^{\circ} \mathrm{C}$, respectivamente, e precipitação de $113 \mathrm{~mm}$.

Foram utilizados 24 bovinos, machos inteiros, de raças taurinas e suas cruzas, em delineamento experimental inteiramente casualizado (DIC), com 2 tratamentos e 3 repetições (baias de $36 \mathrm{~m}^{2}$ ), e cada baia com quatro animais. Os animais foram bloqueados por peso e estado corporal, observando a homogeneidade das variâncias, aplicando o Teste de Levene's.

No início do experimento, o peso corporal inicial médio foi de 319,3 $\pm 11,4 \mathrm{~kg}$ e idade média de 11 meses. Os bovinos foram identificados com brincos numerados conforme o cadastro do Sistema Brasileiro de Identificação e Certificação de Bovinos e Bubalinos (SISBOV). As baias disponibilizaram área de $9,0 \mathrm{~m}^{2}$ por animal, o ambiente era coberto com telhas de cerâmica, com piso de concreto, disponibilizando espaço de cocho de $0,8 \mathrm{~m}$ linear por cabeça, providas de bebedouros de plástico. Foi realizado um calendário de vacinação que antecedeu o experimento. Os animais receberam de forma injetável antiparasitário para controle de endo e ectoparasitas (ingrediente ativo: abamectina, dose de $1 \mathrm{~mL}$ para cada $50 \mathrm{~kg}$ de peso vivo), revitalizante e estimulante orgânico na dosagem de 10mL/animal, vacinas antirrábica e profiláticas do botulismo, da gangrena gasosa, carbúnculo sintomático, enterotoxemia, doença do rim polposo e morte súbita dos ruminantes, e posteriormente suas respectivas doses de reforço. No encaminhamento dos bovinos para o abate foi respeitando o período de carência dos princípios ativos das vacinas exigidas pelo fabricante.

Os animais foram submetidos a um período de adaptação as dietas. Durante cinco dias os animais receberam inicialmente silagem de milho e concentrado. Posteriormente, todos os animais receberam 3 litros de soro de leite nas dietas, aumentando a oferta gradativamente de três em três dias, até a inclusão de 30 litros a partir do $16^{\circ}$ dia. Após a adaptação os animais foram pesados e o soro de leite foi retirado da dieta controle. O período experimental do confinamento foi de 124 dias.

As dietas foram formuladas isoproteicas e isoenergéticas, para ganhos de peso de 1,3 kg/dia seguindo as recomendações do National Research Council (NRC, 2016), com relação volumoso: concentrado de 40:60, contendo $13 \%$ de proteína bruta e 68\% de nutrientes digestíveis totais. Para o cálculo da dieta foi utilizado o software de formulação de dietas Br-Corte®, disponibilizado on-line por Valadares Filho, Costa e Silva e Lopes (2016). As dietas foram 
compostas pelos ingredientes: silagem de milho e concentrado (Tabelas 1 e 2), com acréscimo de soro de leite líquido na dieta do grupo soro. O soro foi incluído ao nível de 14,79\% da matéria seca da dieta (Tabelas 1 e 2). A mistura dos ingredientes do concentrado foi realizada na propriedade, utilizando misturador do tipo vertical (modelo compacto, marca Osório, Itapira/São Paulo - Brasil), fixado no piso, com capacidade para $1.000 \mathrm{~kg}$ por batelada e tempo de mistura de 15 minutos.

Os dados bromatológicos dos componentes da dieta estão descritos na Tabela 1. Para determinação da matéria seca, matéria mineral, extrato etéreo e fibra bruta foram utilizados os métodos descritos na Portaria $n^{\circ} 108$ do MAPA. Para determinação da proteína bruta foi empregado o método da AOAC Method. Para obtenção dos dados referentes à fibra em detergente neutro e fibra em detergente ácido foi utilizado o Compêndio Brasileiro de Alimentação Animal, 2009. Os valores relacionados aos Nutrientes Digestíveis Totais foram obtidos pela metodologia descrita por Kearl (1982).

Tabela 1. Composição química dos ingredientes utilizados nas dietas experimentais, com base na matéria seca.

\begin{tabular}{|c|c|c|c|c|c|c|}
\hline Composição & SM & MM & FAI & FS & $\mathbf{C S}$ & SLL \\
\hline Matéria Seca*, g.kg ${ }^{-1}$ & 305,9 & 870,7 & 893,3 & 872,5 & 949,7 & 72,5 \\
\hline Proteína Bruta, g.kg ${ }^{-1}$ & 65,7 & 81,0 & 144,2 & 446,4 & 96,2 & 74,1 \\
\hline Matéria Mineral, g.kg ${ }^{-1}$ & 70,1 & 11,5 & 84,7 & 55,0 & 39,5 & - \\
\hline Extrato Etéreo, g.kg ${ }^{-1}$ & 24,1 & 36,8 & 256,8 & 25,6 & 17,2 & - \\
\hline Fibra Bruta, g. $\mathrm{kg}^{-1}$ & 256,5 & 12,0 & 78,5 & 40,9 & 340,4 & - \\
\hline Fibra em detergente neutro, g. $\mathrm{kg}^{-1}$ & 467,3 & - & - & - & 590,2 & - \\
\hline Fibra em detergente ácido, g. $\mathrm{kg}^{-1}$ & 293,4 & - & - & - & 440,1 & - \\
\hline Nutrientes Digestíveis Totais, g.kg-1 & 608,0 & - & - & - & - & - \\
\hline
\end{tabular}

$\mathrm{SM}=$ Silagem de milho; $\mathrm{MM}=$ Milho moído; FAI = Farelo de arroz integral $; \mathrm{FS}$ = farelo de soja; $\mathrm{CS}=$ Casca de soja; $\mathrm{SSL}=$ Soro de leite liquido $; *$ com base na matéria natural. 
Tabela 2. Composição das dietas experimentais.

\begin{tabular}{lcc}
\hline Ingrediente & Controle & Soro de leite \\
\hline Silagem de milho, \% & 40,35 & 40,41 \\
Milho moído, \% & 16,94 & 9,21 \\
Soro de leite, \% & - & 14,79 \\
Farelo arroz integral, \% & 14,08 & 12,07 \\
Farelo de soja, \% & 13,26 & 10,94 \\
Casca de soja, \% & 11,53 & 8,98 \\
Calcário calcítico, \% & 0,85 & 0,61 \\
Núcleo mineral ${ }^{*} \%$ & 2,07 & 2,07 \\
Tamponante ${ }^{*}, \%$ & 0,92 & 0,92
\end{tabular}

*Minerplex Confinamento (Monensina) - Nutrifarma®.**TopLac AlKamix (Óxido de Magnésio; Bicarbonato de sódio; Carbonato de cálcio) - Nutrifarma®.

Os animais foram alimentados em dois períodos diários, entre às 07:00 e 07:30 horas e 17:00 e 17:30 horas, sendo o fornecimento de água ad libitum. As sobras dos cochos foram diariamente recolhidas e armazenadas em recipientes plásticos para posterior pesagem e análises laboratoriais.

As pesagens para obtenção dos dados de ganho de peso foram realizadas no início do período de adaptação, no início do experimento, mensalmente, e no final do experimento quando os animais foram conduzidos para o abate. Para realização das pesagens os animais foram submetidos a jejum alimentar de 12 horas, e de forma individual, contidos dentro de uma balança pecuária mecânica para grandes animais (tipo caixa, marca Rinnert, fabricada em Braço do Trombudo/Santa Catarina - Brasil), com capacidade para $1.000 \mathrm{~kg}$ de peso vivo, divisão $0,5 \mathrm{~kg}$, com plataforma 2,40m de comprimento x $1,45 \mathrm{~m}$ de largura, fabricada em madeira. $\mathrm{O}$ ganho de peso total foi calculado pela a diferença entre os pesos final e inicial do animal. O cálculo do ganho de peso médio diário resultou do ganho de peso durante o período considerado, dividido pelo número de dias do experimento.

O consumo de matéria seca foi calculado com base na composição da dieta (\% da MS), o teor de MS do ingrediente (\%), relação: ingrediente/total dieta e relação com o consumo de matéria natural (PACHECO; FABRICIO; CAMERA, 2016).

Após a chegada dos animais ao frigorífico, os mesmos foram submetidos à dieta hídrica por aproximadamente12 horas, período que antecedeu o abate. Posteriormente foram conduzidos para banho (lavação), e de forma individual, para o brete de atordoamento. Na sequência realizou-se a sangria, esfola, evisceração, corte da carcaça (meias carcaças), toalete, pesagem e resfriamento das carcaças. 
As análises qualitativas nas carcaças foram realizadas 24 horas após o abate e resfriamento das mesmas, no músculo Longissimus thoracis.

O rendimento da carcaça foi obtido pela relação entre o peso do animal abatido e o peso da carcaça quente, expresso em porcentagem. Não sendo realizada pesagem das carcaças após o período de 24 horas, ou seja, não foi obtido o peso de carcaça fria.

As medições para determinar a espessura de gordura subcutânea foram realizadas com uso de uma régua na altura da $3^{\mathrm{a}}$ vértebra torácica, onde estava exposto o músculo Longissimus thoracis.

As análises de cor da carne foram realizadas na superfície plana do músculo Longissimus thoracis, sendo todo procedimento feito na carcaça (ARANHA et al., 2018) depois de seccionado da carcaça 24 horas após o abate e resfriamento da mesma. Foram efetuadas três medições para cada animal, utilizando-se colorímetro (Minolta Chroma Meter CR-400) devidamente calibrado e ajustado para operar com iluminante D65 e ângulo de observação de $10^{\circ}$, sendo o mesmo procedimento adotado para determinação da cor da gordura da carcaça, conforme metodologia empregada por Lima (2018). Foi adotada a escala de cor CIE $L^{*} a^{*} b^{*}$, sugerida pela Commission Internationale I'Eclairage, onde a leitura do parâmetro $L^{*}$ representa a luminosidade, com valores variando de 0 a 100 , em que, altos valores para $L^{*}$, ou mais próximos de 100 indicam cor clara a branca, e valores menores, ou mais próximos de 0 , indicam coloração escura a preta. A coordenada $a^{*}$ indica a variação do vermelho para valores próximos de $a^{*}$ positivo, ao verde para valores próximos de $a^{*}$ negativo. Já a coordenada $b^{*}$ indica a variação do amarelo, para valores próximos de $b^{*}$ positivo, e azul, para $b^{*}$ negativo (LANCASTER et al., 1997).

As aferições do $\mathrm{pH}$ e temperatura foram realizadas 24 horas após o abate, no grupo de músculos (Sartorius, Gracilis, Pectineus, Adductor femoris, Semimembranosus, gemeli, Obturator externos, Obturator internus, Quadratum femoris) que formam o corte "coxão mole", utilizando um pHmetro portátil de penetração (marca Hanna Instruments, modelo HI 99163) com calibração de pH e temperatura automáticas, de acordo com as instruções do fabricante.

A avaliação visual e comparativa do teor de marmoreio foi realizada no músculo Longissimus thoracis, sendo adotadas as escalas de avaliação descritas por Müller (1987).

Os dados foram submetidos ao teste de normalidade de Kolmogorv-Smirnov. As variáveis consumo de matéria seca, peso vivo, $\mathrm{L}^{*} \mathrm{e} \mathrm{b}^{*}$ (carne e gordura), $\mathrm{a}^{*}$ (carne), e rendimento de carcaça quente, que apresentaram distribuição normal, foram submetidas à análise de variância, já o teste de Kruskal-Wallis foi utilizado para as variáveis ganho médio diário, a*(gordura), espessura de gordura subcutânea, pH, e temperatura, que não possuíram distribuição normal. Foi utilizado o programa $S A S$ versão university, considerando o nível de significância de $5 \%$. 


\section{RESULTADO E DISCUSSÃO}

Foi verificada diferença $(\mathrm{p}<0,05)$ para o consumo de matéria seca diária, sendo que o grupo alimentado com soro de leite apresentou menor ingestão de matéria seca em relação ao grupo controle, fato que pode estar relacionado com a capacidade de enchimento e limitação física do rúmen, $\mathrm{pH}$ ruminal e digestibilidade do alimento. $\mathrm{O}$ ganho de peso médio diário, peso e rendimento de carcaça quente e espessura de gordura subcutânea, não apresentaram diferença entre os tratamentos $(\mathrm{p}>0,05)$ (Tabela 3$)$.

Tabela 3. Valores referentes ao consumo de matéria seca, ganho de peso médio diário, peso de abate, peso da carcaça quente, rendimento de carcaça quente, espessura de gordura subcutânea e marmoreio de novilhos alimentados com a dieta controle e soro de leite.

\begin{tabular}{lccc}
\hline Variáveis & Controle $^{*}$ & Soro de leite* $^{*}$ & Valor p \\
\hline Consumo de matéria seca, kg.animal & \\
Ganho peso médio diário, kg.animal & -1 \\
.dia & $9,39^{\mathrm{a}} \pm 0,15$ & $8,40^{\mathrm{b}} \pm 0,14$ & 0,008 \\
Peso de abate, $\mathrm{kg}$ & $1,41 \pm 0,06$ & $1,42 \pm 0,05$ & 0,920 \\
Peso da carcaça quente, kg & $497 \pm 19,94$ & $504 \pm 21,36$ & 0,806 \\
Rendimento de carcaça quente, \% & $279,15 \pm 12,54$ & $287,77 \pm 13,16$ & 0,640 \\
Espessura de gordura subcutânea, mm & $56,02 \pm 0,50$ & $56,98 \pm 0,50$ & 0,193 \\
Marmoreio & $5,25 \pm 0,92$ & $6,50 \pm 1,35$ & 0,452 \\
\hline
\end{tabular}

Letras diferentes na mesma linha diferem entre si ao nível de 5\% de significância.

*Valores médios e erro padrão da média.

A capacidade de enchimento e a limitação física do rúmen foram citadas por Anderson et al. (1974), como fatores limitantes. Esses autores observaram que a medida que aumentava a disponibilidade do soro do leite na dieta de vacas leiteiras, essas diminuíam a ingestão de matéria seca. Para cada $1 \mathrm{~kg}$ de sólido ingerido proveniente do soro de leite consumido, ocorreu redução no consumo de 0,7 a $1 \mathrm{~kg}$ de MS/dia. David et al. (2010) atribuíram o menor consumo em bovinos alimentados com soro de leite em razão do efeito de enchimento do rúmen e ao elevado teor energético deste subproduto, oriundo da lactose, carboidrato altamente fermentável que representa cerca de $70 \%$ da matéria seca do soro.

Um dos conceitos relacionados à regulação de consumo é o controle fisiológico, sendo que os animais consomem alimento até atenderem suas exigências energéticas. Assim, a saciedade, nesse caso, agiria como fator fisiológico limitante (COELHO da SILVA, 2011; OLIVEIRA et al., 2017). Fato que pode explicar o menor consumo de matéria seca dos animais alimentados com soro de leite. 
Apesar do pH ruminal não ter sido uma variável estudada no presente trabalho, o $\mathrm{pH}$ do rúmen, que além de ser influenciado pela participação da quantidade de fibra da dieta, também é influenciado pela fermentação e a quantidade de saliva secretada que alteram a produção de ácidos graxos de cadeia curta, que em grandes quantidades no rúmen, causam a diminuição no pH reduzindo o apetite do animal (ALLEN, 1997; DAVID et al., 2010), explicando a diminuição do consumo de matéria seca do grupo alimentado com soro de leite, sem que ocorresse a perda no desempenho dos animais.

Apesar do menor consumo de matéria seca do grupo de animais alimentados com soro de leite, o desempenho dos animais não foi influenciado, sendo que os ganhos médios diários observados apresentaram valores similares, correspondendo às expectativas inicialmente proposta, considerando que a dieta foi calculada para um ganho de 1,3 kg/animal/dia Ao utilizar dietas isoproteicas e isoenergéticas alguns autores não encontraram influência entre os tratamentos no desempenho animal, em dietas com níveis nutricionais parecidos (IGARASI et al., 2008a; MARCONDES et al., 2011; CUSTÓDIO et al., 2018). Marcondes et al. (2011) trabalhando com novilhos de 18 meses de idade, atribuíram os resultados observados ao manejo adotado e a uma possível acidose subclínica.

Os valores semelhantes para peso e rendimento de carcaça obtidos nesse trabalho, foram observados por Igarasi et al. (2008b) e Lima et al. (2013), que atribuíram o fato ao desenvolvimento similar dos animais, em dietas isoproteicas e isoenergéticas. Avaliando substituições da silagem de milho por silagem de girassol sobre as características da carcaça de bovinos Callegaro et al. (2018) não encontraram diferenças no rendimento de carcaça, atribuindo a semelhança dos resultados à similaridade das dietas e do peso de abate dos animais.

Diferenças no rendimento de carcaças poderiam ser esperadas, o que não ocorreu, pois os bovinos utilizados no experimento, apesar de apresentarem a mesma idade, eram oriundos de diversos cruzamentos e as curvas de crescimento podem ser expressas de formas distintas (PACHECO et al., 2005). O rendimento de carcaça também pode ser influenciado pela diferença de peso de abate dos animais, mas com acabamento similar, como o verificado por Chambaz et al. (2003) e por Arboitte et al. (2004), onde animais com a mesma idade e dieta, a medida que aumentou o peso de abate foi observado acréscimo de 0,026\%, valor próximo ao 0,02\% observado por Missio et al. (2013) no rendimento de carcaça, ressaltando a influência do peso corporal, composto por músculo e gordura, para essa característica.

Para espessura de gordura subcutânea (EGS) não foi observada diferença significativa, ( $>0,05)$. Em estudo testando dietas isoproteicas e isoenergéticas Igarasi et al. (2008b) não verificaram diferença para EGS e atribuíram as igualdades observadas a similaridade das dietas e a semelhança racial dos animais estudados, o argumento da similaridade da dieta também é 
respaldada por Climaco et al. (2011) e por Pacheco et al. (2005) quando abateram animais superjovens dos grupos genéticos 5/8Charolês 3/8Nelore e 5/8Nelore 3/8Charolês alimentados com a mesma dieta. Portanto, a diferença na EGS, pode ser mais evidente ao comparar animais alimentados com dietas distintas (BLOCK et al., 2001; SCHOONMAKER et al., 2001; IGARASI et al., 2008b).

A EGS tem alta correlação com o nível energético da dieta (LIMA, 2018), além de ser indicador de acabamento nas carcaças. Aumento linear na EGS foi observado por Arboitte et al. (2004) à medida que o peso de abate dos animais passou de 425 para $510 \mathrm{~kg}$, com acréscimo de 2,76 mm quando o peso de abate mudou de 425 para 467 e com menor acréscimo na EGS quando o peso de abate passou de 467 para $510 \mathrm{~kg}$, aumento de $1 \mathrm{~mm}$.

Os valores encontrados para o marmoreio no músculo Longissimus thoracis foram de

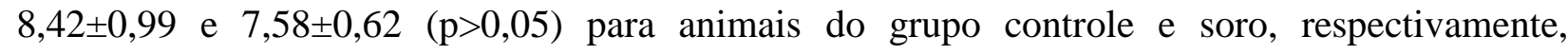
classificando conforme a metodologia descrita por Müller (1987) como marmorização pequena. Os valores similares de marmorização na carcaça corroboram os resultados obtidos por Missio et al. (2013); Lima (2018), onde verificaram similaridade na marmorização das carcaças, atribuindo os resultados a precocidade dos animais durante o abete. Fisiologicamente a gordura apresenta ordem na deposição, em que a do marmoreio ou gordura intramuscular seria a última a ser depositada, embora possa existir outros fatores que influenciam essa característica, como o tipo de dieta, raça e peso de abate (BRONDANI et al., 2006), o tamanho a maturidade do animal (VAN KOEVERING et al., 1995) e o nível energético da dieta (OWENS et al., 1995). Entre todos esses é importante frisar a pré-disposição genética para produzir carne com maior teor de marmoreio.

Os valores relacionados à cor da carne do músculo Longissimus thoracis não apresentaram diferença ( $p>0,05)$, sendo classificadas conforme a luminosidade como carne de cor clara com a intensidade do vermelho e do amarelo alta, conforme descrito por Abularach et al. (1998), em que carne com valores de $\mathrm{L}^{*}=29,68$, são consideradas escuras e $\mathrm{L}^{*}=38,51$ classificadas como clara; já para a intensidade de vermelho o valor de $\mathrm{a}^{*}=14,83$ é baixa e de $\mathrm{a}^{*}=$ 29,27 alta; e para o parâmetro de cor amarelo, o b* $=3,40$ é classificado como baixa e $b^{*}=8,28$ como alta (Tabela 4). 
Tabela 4. Valores para coloração, $\mathrm{pH}$ e temperatura da carne e coloração da gordura de novilhos alimentados com a dieta controle e soro de leite.

\begin{tabular}{lccc}
\hline Variáveis & Controle & Soro de leite & Valor p \\
\hline Cor da carne & & & \\
$\mathrm{L}^{*}$ & $38,77 \pm 0,82^{1}$ & $38,43 \pm 0,69$ & 0,749 \\
$\mathrm{a}^{*}$ & $21,09 \pm 0,58$ & $20,02 \pm 0,58$ & 0,202 \\
$\mathrm{~b}^{*}$ & $12,44 \pm 0,35$ & $11,45 \pm 0,44$ & 0,095 \\
$\mathrm{pH}$ - 24 horas & $6,02^{\mathrm{a}} \pm 0,09$ & $6,35^{\mathrm{b}} \pm 0,10$ & 0,024 \\
Temperatura ${ }^{\circ} \mathrm{C}-24$ & $7,17 \pm 0,27$ & $7,08 \pm 0,29$ & 0,834 \\
horas & & & \\
Cor da gordura & & & \\
$\mathrm{L}^{*}$ & $61,52 \pm 1,47$ & $63,26 \pm 0,84$ & 0,318 \\
$\mathrm{a}^{*}$ & $13,13 \pm 1,59$ & $10,66 \pm 0,99$ & 0,200 \\
$\mathrm{~b}^{*}$ & $13,74 \pm 0,80$ & $14,44 \pm 0,45$ & 0,451 \\
\hline
\end{tabular}

Letras diferentes na mesma linha diferem entre si ao nível de 5\% de significância.

${ }^{1}$ Valores médios e erro padrão da média.

No pré-abate, a cor da carne é muito influenciada pela participação da mioglobina que é modificada à medida que o animal avança na sua idade (MAGGIONI et al., 2012), portanto com bovinos que apresentem similaridade na idade ao abate, a mioglobina não seria o fator determinante, porém Brondani et al. (2006), observaram que a raça e o nível energético da dieta ofertada a bovinos abatidos com 13 e 14 meses influenciaram a coloração da carne. Evidenciando o fato de que a cor está correlacionada com a dieta, idade, raça e peso de abate dos animais.

Por serem animais oriundos de cruzamentos, esperava-se que a raça ou grupos genéticos poderia ocasionar alguma alteração na coloração da carne, como o relatado por Maggioni et al. (2012), em que a carne de animais com maior grau de sangue zebuíno apresentou cor mais escura (menor luminosidade), explicado pela maior frequência de fibras de contração lenta, com metabolismo oxidativo e de coloração vermelha, e maior quantidade de mioglobina à medida que eleva a idade de abate. Como os animais foram distribuídos nos tratamentos procurando não favorecer peso, idade e grupos genéticos esses efeitos sobre a coloração da carne não foram observados.

Os valores de $\mathrm{pH}$ observados na carne após 24 horas de resfriamento das carcaças apresentaram diferenças $(\mathrm{p}<0,05)$ entre as dietas testadas. De acordo com os resultados observados, o pH encontrado na presente pesquisa foi considerado alto, porém estes valores não influenciaram na coloração, o que leva a crer que outros atributos como baixa idade de abate, o 
bom desempenho em confinamento que proporcionou bom acabamento das carcaças tenham se sobressaído para que a carne apresentasse coloração adequada para o consumidor. Carnes mais escuras apresentam $\mathrm{pH}$ elevado, em virtude das proteínas miofibrilares da carne apresentarem maior capacidade de ligação com a água, se tornando uma estrutura oclusa com reduzidos espaços extracelulares e elevada capacidade de retenção de água, dificultado a difusão do oxigênio, possibilitando maior absorção da luz incidente e baixa dispersão da mesma na superfície da carne (ABRIL et al., 2001).

$\mathrm{O}$ elevado $\mathrm{pH}$ observado pode ter influência direta da temperatura e da velocidade do vento da câmara fria, como as carcaças dos animais ficaram armazenadas juntamente com carcaças de outros animais abatidos no dia, porque foi seguido o fluxo normal de abate do frigorífico, que é dado conforme a demanda, e também a temperatura da câmara fria é controlada conforme procedimentos utilizados pelo frigorífico, é possível que o resfriamento das mesmas não tenha ocorrido de forma homogênea e com velocidade adequada para atingir o patamar desejado.

Os valores para temperatura, encontrados nesse trabalho, se aproximam do mencionado por Nassu et al. (2016), que avaliaram características de carcaças cuja temperatura atingida foi no máximo $7^{\circ} \mathrm{C}$ após o resfriamento, atendendo a legislação vigente (BRASIL, 1996).

O entendimento da influência que a temperatura de resfriamento exerce sobre as carcaças é fundamental para que durante seu armazenamento não ocorram alterações que possam afetar as características organolépticas da carne. Quando as carcaças são resfriadas rapidamente, atingindo temperatura inferior a $10^{\circ} \mathrm{C}$, sem que o $\mathrm{pH}$ esteja abaixo de 6,0 , sem que o rigor mortis tenha se estabelecido completamente, acontece encurtamento excessivo das fibras musculares, o que irá interferir negativamente na maciez e capacidade de retenção de água da carne (SILVA, 2017).

Para a coloração da gordura os valores medidos foram $L^{*} 63,26 \pm 0,84, a^{*} 10,66 \pm 0,99$, e $b^{*} 14,44 \pm 0,45$ para bovinos do grupo com soro e $L^{*} 61,52 \pm 1,47, a^{*} 13,13 \pm 1,59$, e $b^{*} 13,74 \pm 0,80$ animais do grupo controle, indo de encontro com os observados por Lima (2018), que 24 horas após o abate não verificou diferença para os parâmetros $L^{*} e b^{*}$ na gordura de animais terminados em confinamento convencional, baseado em silagem de milho e concentrado comercial; confinamento alto grão; e terminação a pasto, com pastagens de inverno e suplementação energética de milho. No entanto, $\mathrm{a}^{*}$ foi menor para animais terminados a pasto, indicando uma carne mais vermelha para os animais terminados em confinamento.

Lima (2018) relaciona a coloração amarela da gordura com a existência de carotenos presente nas pastagens, fato que pode explicar a ausência de discrepância na coloração nesse trabalho, considerando que os animais receberam a mesma fonte de volumoso oriunda de silagem de milho. Leão et al. (2012), apesar de não encontrarem diferença na coloração da carne de 
cordeiros, demonstraram que a silagem de milho possui maior concentração de carotenoides comparada com a cana-de-açúcar: betacaroteno= 3,32 vs 0,$40 ;$ luteína $=4,56$ vs 0,45 e zeaxantina $=3,93$ vs $0,43(\mathrm{mg} / 100 \mathrm{~g})$, respectivamente.

\section{CONCLUSÃO}

Os animais alimentados com soro de leite se mostraram mais eficientes do ponto de vista alimentar quando comparado com o grupo controle, apresentando menor consumo de matéria seca para ganho de peso similar.

O uso de soro de leite, no nível de inclusão utilizado nesse trabalho não afetou o desempenho dos animais, assim como não alterou a coloração da carne e da gordura.

\section{REFERÊNCIAS}

ABRIL, M. et al. Beef colour evolution as a function of ultimate $\mathrm{pH}$. Meat Science, v.58, n.1, p. 69-78, 2001. Disponível em: https://doi.org/10.1016/S0309-1740(00)00133-9. Acesso em: 20 fev. 2019.

ABULARACH, Maria Lourdes. S. et al. Características de qualidade do contrafilé ( $m$. L. dorsi) de touros jovens da raça Nelore. Revista Ciência e Tecnologia de Alimentos, v.18, n. 2, p. 205210, 1998. Disponível em: http://dx.doi.org/10.1590/S0101-20611998000200012. Acesso em: 10 fev. 2019.

ALLEN, Michael. S. Relationship between fermentation acid production in the rumen and the requirement for physically effective fiber. Journal of Dairy Science, v. 80, n.7, p.1447-1462, 1997. Disponível em: https://doi.org/10.3168/jds.S0022-0302(97)76074-0. Acesso em: 15 fev. 2019

ALLEN, Michael. S. Effects of diet on short-term regulation of feed intake by lactating dairy cattle. Journal of Dairy Science, v. 83, n. 7, p. 1598-1624, 2000. Disponível em: https://doi.org/10.3168/jds.S0022-0302(00)75030-2. Acesso em: 10 jan. 2019.

ALENCASTRO FILHO, Aluísio de. et al. Ganho em peso médio diário em diferentes grupos genéticos de bovinos de corte. PUBVET- Publicações em Medicina Veterinária e Zootecnia, v. 11, n.1, p. 87-90, 2017. Disponível em: https://doi.org/10.22256/pubvetv11n1.87.90. Acesso em: 13 maio 2019.

ANDERSON, M. J. et al. Feeding liquid whey to dairy cattle. Journal of Dairy Science, v.57, n.10, p.1206-1210, 1974. Disponível em: https://doi.org/10.3168/jds.S0022-0302(74)85038-1. Acesso em: 20 jan. 2019.

ARANHA, Aline Sampaio. et al. Performance, carcass and meat characteristics of two cattle categories finished on pasture during the dry season with supplementation in different forage allowance. Arquivo Brasileiro de Medicina Veterinária e Zootecnia, v. 70, n. 2, p. 517-524, 2018. Disponível em: http://dx.doi.org/10.1590/1678-4162-9576. Acesso em: 10 maio 2019. 
ARBOITTE, Miguelangelo Ziegler. et al. Composição física da carcaça, qualidade da carne e conteúdo de colesterol no músculo Longissimus dorsi de novilhos 5/8 Nelore - 3/8 Charolês terminados em confinamento e abatidos em diferentes estádios de maturidade. Revista Brasileira de Zootecnia, v. 33, n. 4, p. 959-968, 2004. Disponível em: http://dx.doi.org/10.1590/S151635982004000400016. Acesso em: 30 mar. 2019.

ASSOCIAÇÃO BRASILEIRA DAS INDÚSTRIAS EXPORTADORAS DE CARNES (ABIEC). Beff report - Perfil da pecuária no Brasil. São Paulo: ABIEC, 2018. Disponível em :< http://www.abiec.com.br/controle/uploads/arquivos/sumario2019portugues.pdf?fbclid=IwAR0pf 5-dWpbaV-Egq84qFZIPgeXnI1Glz-oadeT11EBL2hwwzbtV9QxoJXE>. Acesso em: 18 jun. 2019.

BLOCK, H. C. et al. Manipulation of cattle growth to target carcass quality. Journal of Animal Science, v. 79, n.1, p. 133-140, 2001. Disponível em: https://doi.org/10.2527/2001.791133x. Acesso em: 12 maio 2019.

BONILHA, Sara Figueiredo Martins. et al. Efeitos da seleção para peso pós-desmame sobre características de carcaça e rendimento de cortes cárneos comerciais de bovinos. Revista

Brasileira de Zootecnia, v. 36, n. 5, p. 1275-1281, 2007. Disponível em: http://dx.doi.org/10.1590/S1516-35982007000600008. Acesso em:12 jan. 2019.

BORGES, Ana Carolina Costa; SOUZA, Stefania Márcia de Oliveira. Controle de temperatura: importância e influência na qualidade da carne bovina. PUBVET- Publicações em Medicina Veterinária e Zootecnia, v.13, n. 7, p. 1-14, 2019. Disponível em: https://doi.org/10.31533/pubvet.v13n7a366.1-14. Acesso em: 15 set. 2019.

BRASIL. Ministério da Agricultura e Reforma Agrária. Portaria no. 108, de 4 de setembro de 1991. Métodos analíticos para controle de alimentos para uso animal. Brasília: Diário Oficial da União, 17/09/1991a (seção 1).

BRASIL. Ministério da Agricultura, Pecuária e Abastecimento. Portaria 108, de 4 de setembro de 1991. Métodos analíticos para controle de alimentos para uso animal. Método 11 (fibra bruta). Brasília: Diário Oficial da União (17/09/1991b).

BRASIL. Ministério da Agricultura, Pecuária e Abastecimento (BR). Quantidade de Abate Estadual por Ano/Espécie. Disponível em:

http://sigsif.agricultura.gov.br/sigsif_cons/!ap_abate_estaduais_cons?p_select=SIM;p_ano=2018; p_id_especie=9. Acesso em: 20 fev. 2019.

BRASIL. Ministério da Agricultura, Pecuária e Abastecimento (BR). Portaria n. ${ }^{\circ}$ 304, de 22 de abril de 1996. Estabelecimentos de abate de bovinos, bubalinos e suínos somente poderão entregar carnes e miúdos para comercialização com temperatura de até 7 (sete) graus centígrados. Diário Oficial da União. 23 abr 1996. Of. no 80/96; D.O.U., 23/04/1996. Seção 1, p.6856. Disponível em:

http://sistemasweb.agricultura.gov.br/sislegis/action/detalhaAto.do?method=consultarLegislacao Federal. Acesso em: 20 fev. 2019.

BRONDANI, Ivan Luiz et al. Composição física da carcaça e aspectos qualitativos da carne de bovinos de diferentes raças alimentados com diferentes níveis de energia. Revista Brasileira de Zootecnia. São Paulo, v. 35, n. 5, p. 2034-2042, 2006. Disponível em: http://dx.doi.org/10.1590/S1516-35982006000700022. Acesso em: 05 set. 2019. 
CALLEGARO, Alisson Marian. et al. Avaliação da inclusão parcial da silagem de girassol (Helianthus annuus, L.) sobre as características quantitativas da carcaça de bovinos terminados em confinamento. Revista Brasileira de Nutrição Animal, v.12, n.1, p. 23 -29, 2018. Disponível em: http://www.nutricaoanimal.ufc.br/seer/index.php/higieneanimal/article/view/448. Acesso em: 12 jul. 2019.

CARVALHO, José Rodolfo Reis de. et al. Performance, carcass characteristics and ruminal pH of Nellore and Angus young bulls fed a whole shelled corn diet. Journal of Animal Science, v. 94, n. 6, p. 2451-2459, 2016. Disponível em: https://doi.org/10.2527/jas.2015-0162. Acesso em: 18 maio 2019.

CHAMBAZ, Alain. et al. Meat quality of Angus, Simmental, Charolais and Limousin steers compared at the same intramuscular fat content. Meat Science, v. 63, n. 4, p. 491-500, 2003. Disponível em: https://doi.org/10.1016/S0309-1740(02)00109-2. Acesso em: 07 jun. 2019.

CLIMACO, Saulo Malaguido et al. Características de carcaça e qualidade da carne de bovinos de corte de quatro grupos genéticos terminados em confinamento. Revista Brasileira de Zootecnia, v. 40, n.12, p. 2791-2798, 2011. Disponível em: http://dx.doi.org/10.1590/S151635982011001200025. Acesso em: 20 jan. 2019.

COELHO da SILVA, José Fernando. Mecanismos reguladores de consumo. In BERCHIELLI T.T.; PIRES A.V.; OLIVEIRA S. G de. Nutrição de Ruminantes. Jaboticabal: Funep, p. 61-82, 2011.

CUSTODIO, Sérgio Antoni Schwartz. et al. Desempenho de bovinos de corte em confinamento alimentados com diferentes forragens e alojados em baias individuais ou coletivas. Archives of Veterinary Science, v. 23, n.1, p. 33-43, 2018. Disponível em: https://revistas.ufpr.br/veterinary/article/view/45070/35096. Acesso em: 09 fev. 2019.

DAVID, Flavia Maria et al. Efeito da adição de soro de leite sobre a digestibilidade aparente e os parâmetros sanguíneos de vacas secas. Arquivo Brasileiro de Medicina Veterinária e Zootecnia, v. 62, n. 5, p. 1183-1190, 2010. Disponível em: http://dx.doi.org/10.1590/S010209352010000500022. Acesso em: 28 jun. 2019.

FERREIRA, Sérgio F. et al. Fatores que afetam o consumo alimentar de bovinos. Arquivos de Pesquisa Animal. v. 2, p.1, p. 9-19, 2013. Disponível em:

https://www2.ufrb.edu.br/apa/component/phocadownload/category/13-ano-13-vol2. Acesso em: 12 mar. 2019.

IGARASI, Mauricio Scoton. et al. Desempenho de bovinos jovens alimentados com dietas contendo grão úmido de milho ou sorgo. Revista Brasileira de Zootecnia, v. 37, n. 3, p. 513519, 2008a. Disponível em: http://dx.doi.org/10.1590/S1516-35982008000300017. Acesso em: 30 jan. 2019.

IGARASI, Mauricio Scoton. et al. Características de carcaça e parâmetros de qualidade de carne de bovinos jovens alimentados com grãos úmidos de milho ou sorgo. Revista Brasileira de Zootecnia, v. 37, n. 3, p. 520-528, 2008b. Disponível em: https://dx.doi.org/10.1590/S151635982008000300018 . Acesso em: 30 jan. 2019.

KEARL, Leonard. C. Nutrient requirements of ruminants in developing countries. Logan: International Feedstuffs Institute, 1982. 381p. 
LANCASTER, Jane E. et al. Influence of Pigment Composition on Skin Color in a Wide Range of Fruit and Vegetables. Journal of the American Society For Horticultural Science, v.122, n. 4, p. 594-598, 1997. Disponível em: https://doi.org/10.21273/JASHS.122.4.594. Acesso em: 10 fev. 2019.

LEÃO, André Gustavo et al. Características físico-químicas e sensoriais da carne de cordeiros terminados com dietas contendo cana-de-açúcar ou silagem de milho e dois níveis de concentrado. Revista Brasileira de Zootecnia, v. 41, n. 5, p. 1253-1262, 2012. Disponível em: http://dx.doi.org/10.1590/S1516-35982012000500024. Acesso em:15 jan. 2019.

LEITE, Daniel Terra et al. Composição física da carcaça e qualidade de carne de bovinos superjovens inteiros Charolês e Charolês x Nelore. Acta Scientiarum. Animal Science, v. 28, n. 4, p. 461-467, 2006. Disponível em: https://doi.org/10.4025/actascianimsci.v28i4.609. Acesso em: 13 maio 2019.

LOPES, M. A.; MAGALHÃES, G. P. Análise da rentabilidade da terminação de bovinos de corte em condições de confinamento: um estudo de caso. Arquivo Brasileiro de Medicina

Veterinária e Zootecnia, v. 57, n. 3, p. 374-379, 2005. Disponível em:

http://dx.doi.org/10.1590/S0102-09352005000300016. Acesso em: 29 maio 2019.

LOPES, Leandro Sâmia et al. Características de carcaça e cortes comerciais de tourinhos Red Norte e Nelore terminados em confinamento. Revista Brasileira de Zootecnia, v. 41, n. 4, p. 970-977, 2012. Disponível em: http://dx.doi.org/10.1590/S1516-35982012000400020. Acesso em: 03 jun. 2019.

LIMA, Patrícia de Oliveira et al. Características de carcaça e componentes de peso vivo de bezerros recebendo diferentes dietas líquidas. Revista Ciência Rural, v. 43, n.11, p. 2056-2062, 2013. Disponível em: http://dx.doi.org/10.1590/S0103-84782013005000124. Acesso em: 12 maio 2019.

LIMA, Horácio Luis de. Diferentes sistemas de terminação e seus efeitos na carcaça e carne de novilhos angus superprecoces. 2018. 69p. Dissertação (Mestrado). Universidade do Estado de Santa Catarina - UDESC, Chapecó, 2018.

MAGGIONI, Daniele et al. Grupos genéticos e graus de acabamento sobre qualidade da carne de bovinos. Semina: Ciências Agrárias, v. 33, n.1, p. 391-402, 2012. Disponível em: http://dx.doi.org/10.5433/1679-0359.2012v33n1p391. Acesso em: 09 fev. 2019.

MARCONDES, Marcos Inácio et al. Eficiência alimentar de bovinos puros e mestiços recebendo alto ou baixo nível de concentrado. Revista Brasileira de Zootecnia, v.40, n.6, p. 1313-1324, 2011. Disponível em: http://dx.doi.org/10.1590/S1516-35982011000600021. Acesso em: 08 fev. 2019.

MARTINS, Cátia Arruda. Efeito do pH final sobre a qualidade da carne de bovinos da raça Nelore. Dissertação (Mestrado). 2017. 73p. Instituto Superior de Agronomia/Faculdade de Medicina Veterinária - Universidade de Lisboa, 2017.

MELO, Aurélio Ferreira et al. Fatores que influenciam na qualidade da carne bovina: Revisão. PUBVET- Publicações em Medicina Veterinária e Zootecnia, v.10, n.10, p.785-794, 2016. Disponível em: http://dx.doi.org/10.22256/pubvet.v10n10.785-794. Acesso em: 27 jan. 2019. 
MISSIO, Régis Luis et al. Características da carcaça de vacas de descarte abatidas com diferentes pesos. Revista Ciência Agronômica, v. 44. n. 3, p. 644-651. Disponível em:

http://ccarevista.ufc.br/seer/index.php/ccarevista/article/view/1879/845. Acesso em: 20 maio 2019.

MORELLI, Marcela et al. Influência do uso de coprodutos no balanço de nutrientes de bovinos em confinamento. In: SIMPÓSIO INTERNACIONAL SOBRE GERENCIAMENTO DE RESÍDUOS AGROPECUÁRIOS E AGROINDUSTRIAIS, 5, 2017, Foz do Iguaçu, PR. Anais... [....]. Concórdia, SC, 2017. p.7.

MÜLLER, Lauro. Normas para avaliação de carcaças e concurso de carcaças de novilhos. Santa Maria: Universidade Federal de Santa Maria (UFSM), 1987.

NASSU, RenataTieko et al. Características da carcaça e qualidade da carne de bovinos terminados em sistema de integração lavoura-pecuária. Veterinária e Zootecnia, v. 23, n. 4, p. 637-641, 2016. Disponível em: https://doi.org/10.35172/rvz.2016.v23.399. Acesso em: 12 fev. 2019.

OLIVEIRA, Bruna Cristhina de et al. Mecanismos reguladores de consumo em bovinos de corte. Revista Eletrônica NutriTime, v.14, n. 4, p. 1-10, 2017. Disponível em; https://www.nutritime.com.br/arquivos_internos/artigos/Artigo_433.pdf. Acesso em: 14 maio 2019.

OWENS, Fredric. N et al. Review of some aspects of growth and development of feedlot cattle. Journal of Animal Science, v. 73, n.10, p. 3152-3172, 1995. Disponível em: https://doi.org/10.2527/1995.73103152x. Acesso em: 15 jul. 2019.

PACHECO, Paulo Santana et al. Desempenho de novilhos jovens e superjovens de diferentes grupos genéticos terminados em confinamento. Revista Brasileira de Zootecnia, v. 34, n. 3, p. 963-975, 2005. Disponível em: http://dx.doi.org/10.1590/S1516-35982005000300030. Acesso em: 10 jun. 2019.

PACHECO, Paulo Santana.; FABRICIO, Edom.; CAMERA, Angelina. Análise conjunta de indicadores financeiros na viabilidade econômica do confinamento de bovinos no Rio Grande do Sul em diferentes épocas do ano. Revista Agropampa, v.1, n.1, p. 86-99, 2016. Disponível em: https://www.researchgate.net/publication/312850043. Acesso em: 10 jun. 2019.

PASCHOALOTO, Josimari Regina. Protocolos experimentais de confinamento para bovinos Nelore alimentados com dietas contendo glicerina bruta. 2016. 48p. Tese (Doutorado em Zootecnia) - Faculdade de Ciências Agrárias e Veterinárias, Universidade Estadual Paulista UNESP, Jaboticabal, 2016.

SCHOONMAKER, Jon P et al. Effect of age at feedlot entry on performance and carcass characteristics of bulls and steers. Journal of Animal Science, v. 80, n. 9, p. 2247-2254, 2002. Disponível em: https://doi.org/10.1093/ansci/80.9.2247. Acesso em: 08 maio 2019.

SILVA, Guilherme Portes et al. Custos de confinamento de bovinos de corte no município de Colômbia, SP. Revista IPecege, v. 4, n. 4. p. 7-15, 2019. Disponível em: https://doi.org/10.22167/r.ipecege.2018.4.7. Acesso em: 01 jun. 2019. 
SILVA, Igor Gustavo de Souza. Carne PSE (Pale, Soft, Exudative) e DFD (Dark, Firm, Dry) em abate industrial de bovinos. (Monografia). Brasília (DF). Universidade de Brasília/Faculdade de Agronomia e Medicina Veterinária; 2017.

VALADARES FILHO, Sebastião de Campos.; COSTA E SILVA, Luiz Fernando.; LOPES, Sidinei Antônio. BR-CORTE 3.0. Cálculo de exigências nutricionais, formulação de dietas e predição de desempenho de zebuínos puros e cruzados, 2016. Disponível em www.brcorte.com.br. Acesso em: 10 ago. 2018.

VAN KOEVERING, M. T. et al. Effect of time on feed on performance of feedlot steers, carcass characteristics, and tenderness and composition of longissimus muscle. Journal of Animal Science, v.73, n.1, p. 21-28, 1995. Disponível em: https://doi.org/10.2527/1995.73121x. Aceso em: 28 de maio 2019.

VAZ, Fabiano Nunes et al. Fatores relacionados ao rendimento de carcaça de novilhos ou novilhas superjovens, terminados em pastagem cultivada. Ciência Animal Brasileira, v.11, n.1, p. 53-61, 2010. Disponível em: https://doi.org/10.5216/cab.v11i1.6747. Acesso em: 20 jun. 2019. 